\title{
Peritonitis and Necrotizing Hepatitis in Ara ararauna Caused by a Foreign Body
}

\author{
Larissa Justino', Maisa Fabiana Menck-Costa' ${ }^{2}$, Ana Aparecida Correa Xavier ${ }^{3}$, Marielen de Souza'2, \\ Beatriz Queiroz dos Santos ${ }^{2}$, Ana Paula Frederico Rodrigues Loureiro Bracarense ${ }^{3}$ \& Ana Angelita Sampaio Baptista ${ }^{2}$
}

\begin{abstract}
Background: The ingestion of foreign bodies in parrots has already been described and associated with the curious behavior of the birds or with stressful conditions. Foreign bodies in the gastrointestinal tract are usually diagnosed through clinical signs, laboratory tests, and radiographic findings in the historical data. Foreign bodies are usually metallic and can lodge in any segment of the gastrointestinal tract, commonly found in the proventricle and gizzard. This study investigated a case of necrotizing hepatitis due to a foreign body in Ara ararauna (Linnaeus, 1758).

Case: An approximately 9-month-old specimen of caninde macaw, had sudden death and was referred for autopsy. The macroscopic examination revealed a fibrous, thick, reddish membrane involving the left hepatic lobe and partially the gizzard in continuity with the peritoneum. Inside the capsule, the liver had a friable and necrotic appearance and the gizzard had a focal perforation area containing a foreign body (gavage tube feeding). We performed the histopathological examination of the liver and gizzard and observed that the membrane surrounding the liver and partially the gizzard had a chronic inflammatory process with a marked proliferation of fibrous tissue and fibrin deposition. The hepatic parenchyma of the left lobe showed diffuse and marked necrosis, with signs of ischemic necrosis. In the region of transmural perforation of the gizzard, the mucosa showed a focal area of extensive necrosis accompanied by the presence of intralesional bacteria. The lesions observed are attributed to the perforation of the organs by the foreign body. It is not known whether the bird ingested the object accidently during food handling as a young or due to the curious behavior of the bird or even the stress it may have been exposed to. The post mortem examination revealed localized peritonitis and encapsulating necrotizing hepatitis, focally extensive and accentuated, associated with foreign body perforation.

Discussion: The curious habit of parrots, can provide the ingestion of foreign bodies, in which they lodge in the gastrointestinal tract. Generally, the clinical signs are nonspecific, however, proventricular impaction, stasis and even perforations in the mucosa of organs can be observed. In the present study, we suspect that the Caninde macaw accidentally ingested a tube feeding during management as a young. This object lodged in the bird's ventricle, perforating the organ and reaching the liver, due to intimate contact with the gizzard, providing a picture of ventriculitis and necrotizing hepatitis. Necrotizing hepatitis due to foreign body has been reported in the literature due to ingestion of perforating foreign body with lesion in the left ventricle and lobe, however we have no knowledge of reports with the presence of a capsule involving the left hepatic lobe, similar to a capsule like this, we understand that our report is the first description of encapsulating necrotizing hepatitis in birds. We believe that this capsule of connective tissue was formed, due to the inflammatory process in the peritoneal cavity, in birds the deposition of fibrin can form a structure similar to a capsule, in order to trap cells and the agent responsible for inflammation, preventing septicemia. Transmural perforation in the gizzard, observed in this case, allowed bacterial translocation that may have contributed to the worsening of the chronic condition and death due to the accumulation of toxins or bacterial translocation of the gastric tract, leading to liver infection and sepsis. We concluded that the presence of the perforating foreign body was responsible for the peritonitis and encapsulating necrotizing hepatitis in Ara ararauna.
\end{abstract}

Keywords: Ara ararauna, perforating foreign body, peritonitis, necrotizing hepatitis encapsulanting. 


\section{INTRODUCTION}

Ara ararauna belongs to the order of Psittaciformes, popularly known as "Canindé macaw" [10], blue and yellow macaw [12]. The species can be marketed as a pet, as long as the busineeses and farms are licensed by competent environmental agencies $[10,11]$. The curious behavior of parrots, along with stressful situations [5], favors the ingestion of objects [1]. Foreign bodies in the gastrointestinal tract are usually diagnosed through clinical signs, laboratory tests, and radiographic findings in the historical data. The main signs include anorexia, weight loss, and lethargy [7]. Nevertheless, birds generally show mild clinical signs when they are ill, since the lack of physical fitness in groups can lead to loss of social position or make them vulnerable to predators [14]. Foreign bodies are usually metallic and can lodge in any segment of the gastrointestinal tract, commonly found in the proventricle and gizzard [5]. This study reported a case of peritonitis and necrotizing hepatitis due to foreign bodies in Ara ararauna.

\section{CASE}

A 9-month-old Canindé macaw, Ara ararauna, died suddenly and was referred to the Avian Medicine Laboratory-LMA/UEL for autopsy. According to its owner, the bird was fed with a mixture of seeds, commercial feed, fruits, vegetables and received drinking water ad libitum, and lived in a $40 \mathrm{~m}^{2}$ enclosure divided into a solarium and shaded area and lived with another bird of the same species, with no history previous diseases. During the autopsy, liver and gizzard fragments were collected and fixed in a buffered formalin solution (10\%). Subsequently, the tissues were sent to the Animal Pathology Laboratory of the State University of Londrina (UEL), where they were embedded in paraffin, sectioned, and the slides were stained with hematoxylin and eosin (HE) and histological Gram ${ }^{1}$

The autopsy revealed a fibrous, thick, reddish membrane in the internal examination of the coelomic cavity, involving part of the liver, the gizzard partially and in continuity with the peritoneum, similar to a capsule (Figure 1A). At cut, we observed the left hepatic lobe (Figure 1B), which was diffusely and markedly dark red, friable, and necrotic in appearance (Figure 1C). The right hepatic lobe was not encapsulated; however, it presented fibroelastic consistency, a slight increase in size, pallor, an evident lobular pattern, as well as parenchymal hepatic degeneration, focal, extensive, and discrete. The macroscopic findings indicated the diagnosis of encapsulating necrotizing hepatitis that was focally extensive and accentuated.

The gizzard was covered by the same fibrous capsule. In the serosa, we observed an extensive focal area and a transmural perforation that extended up to the lumen (Figure 1D). Inside the gizzard, a plastic object was observed, approximately $3 \mathrm{~cm}$ long, compatible with a handmade tube feeding (Figure 1E), which went beyond the organ wall and reached the liver parenchyma (Figure $1 \mathrm{~F}$ ).

The histological evaluation showed that the capsule that enveloped the liver (Figure 2A) was a marked proliferation of fibrous tissue with the presence of fibrin, resulting from a chronic inflammatory process. Histology of Gram showed myriads of Gram-positive bacteria on the visceral face of the fibrous capsule of the liver (Figure 2B). The encapsulated left lobe had mild vascular congestion and hepatocyte disorganization. The image magnification showed severe hepatocyte vacuolar degeneration (Figure 2C). The aid of Gram staining in the histological sections of the left lobe of the liver displayed a moderate presence of gram-positive bacteria in the liver parenchyma, with a predominance of bacilli (Figure 2D). In the transmural perforation region of the gizzard, the mucosa showed a focal area of extensive necrosis with the presence of intralesional bacteria. In the right lobe, which was intact, the sinusoids were moderately and engorged diffusely by erythrocytes, and the hepatocytes presented diffuse and moderate intracytoplasmic vacuolization.

\section{DISCUSSION}

The presence of foreign bodies in the gizzard and proventricle are commonly reported in parrots, ratites, and waterfowl, promoting pictures of proventricular impaction, stasis, and ulcerative lesions with signs of regurgitation and/or anorexia [15]. The curious habit of parrots facilitates the ingestion of foreign bodies, which in most cases, are macerated in the gizzard and can cause injuries and even perforations in the organ mucosa [6].

We suspect that the macaw (Ara ararauna) under study accidentally ingested the gavage probe, during food handling, since the bird was raised in captivity, and chicks in these conditions need help with feeding [14]. For the diagnosis of foreign bodies in birds, the 


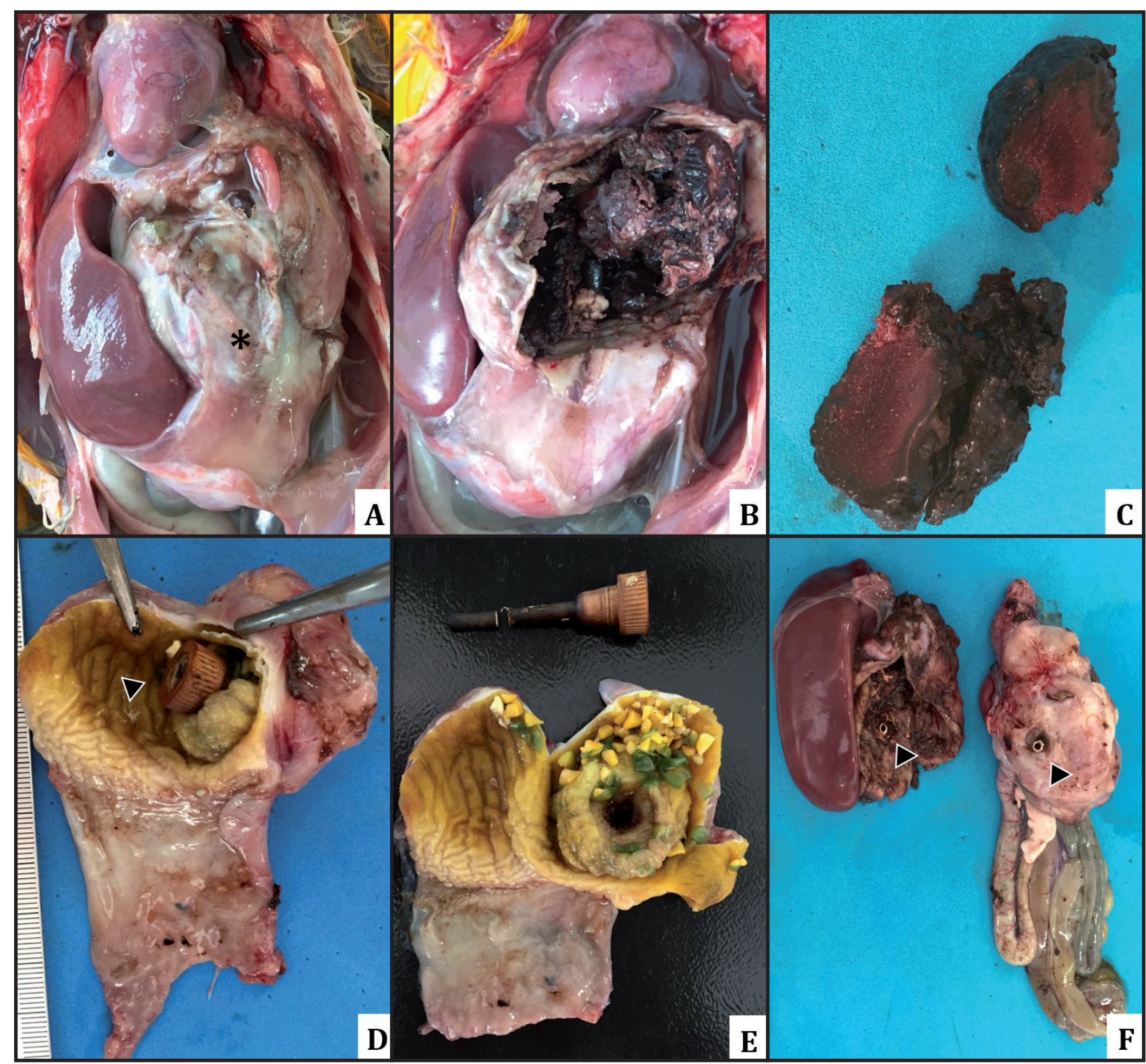

Figure 1. Macroscopic lesions of the organs in an Ara ararauna. A- Liver: fibrous connective tissue capsule covering the left lobe (asterisk). B- Liver: opening of the connective tissue capsule, in its presence the left lobe of the liver with a friable and necrotic aspect. C- Liver: fragments of the left hepatic lobe with a friable and necrotic aspect. D- Gizzard: presence of a plastic foreign body (arrowhead) perforating inside the gizzard. E- Perforating plastic foreign body $(3 \mathrm{~cm})$ removed from the inside of the gizzard. F- Presence of a transmural perforating object in the ventricle and in the left lobe of the liver (arrowheads).

use of radiological examination is recommended [13]. Foreign body necrotizing hepatitis has already been reported in Cacatua alba due to ingestion of perforating foreign bodies with lesion in the left ventricle and lobe [8]. Although the case is similar to that described in this report, the authors did not report the presence of a capsule involving the left hepatic lobe. Therefore, we understand that our report is the first description of encapsulating necrotizing hepatitis in birds.

According to Taylor [18], birds have well-defined pleural, pericardial, and peritoneal cavities. The inflammatory process in the peritoneal cavity causes peritonitis, as observed in this case. The presence of the capsule and connective tissue with a cocoon characteristic was observed covering the left hepatic lobe, similar to encapsulating sclerosing peritonitis, in which a thick whitish membrane surrounds the intestine and other organs $[2,17]$. However, we did not observe the covering of the intestine by the fibrous capsule; therefore, we understand that it is an encapsulating peritonitis. In birds, inflammatory stages occur more quickly than in mammals, and the intensity and type of the inflammatory response depend on the tissue injured, process duration, and individual response capacity. 


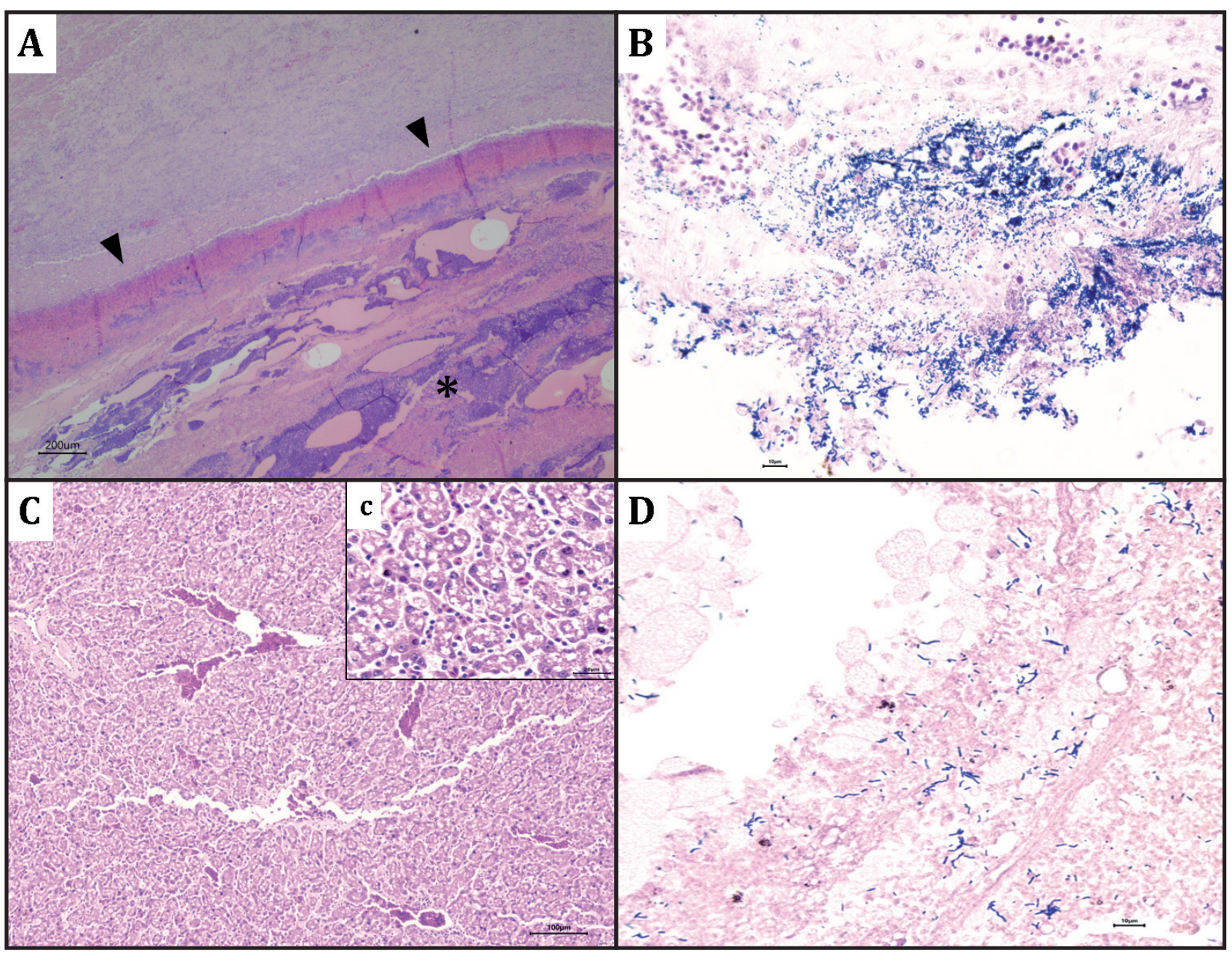

Figure 2. Microscopic lesions in the liver of one Ara ararauna. A- Fibrous capsule: a thick capsule of fibrous tissue (arrowhead) surrounding an area of marked diffuse necrosis $(*)$ [HE; bar $=200 \mu \mathrm{m}$ ]. B- Fibrous capsule: myriade of gram-positive bacteria on the visceral face of the liver fibrous capsule [Gram Goodpasture; bar $=10 \mu \mathrm{m}$ ]. C- Mild vascular congestion and hepatocyte disorganization [HE; bar= $100 \mu \mathrm{m}]$. Insert: severe hepatocytes vacuolar degeneration [HE; bar $=20 \mu \mathrm{m}$ ]. D- Moderate presence of gram-positive bacteria on the hepatic parenchyma, with a bacilli majority [Gram Goodpasture; bar $=10 \mu \mathrm{m}]$.

In addition, the presence of necrotic tissue intensifies and maintains inflammation [3]. In the inflammatory process, the release of vasoactive amines by mast cells provides vascular changes [3] that result in fibrin deposition. Subsequently, there is an intense granulomatous reaction and an increase in the number of macrophages [16], that accumulate around the necrotic debris [3]. Fibrin deposition can form a capsule-like structure that traps cells and the agent responsible for inflammation [4], preventing septicemia [9].

Transmural perforation in the gizzard, observed in this case, allowed bacterial translocation that may have contributed to the worsening of the chronic condition, culminating in death due to the accumulation of toxins or bacterial translocation of the gastric tract, leading to liver infection and sepsis.

The presence of a perforating foreign body was responsible for the condition of peritonitis and necrotizing hepatitis encapsulating in Ara ararauna.

\section{MANUFACTURER}

${ }^{1}$ Vetec Química Fina Ltda. Duque de Caxias, RJ, Brazil.

Declaration of interest. The authors report no conflicts of interest. The authors alone are responsible for the content and writing of paper. 


\section{REFERENCES}

1 Adamcak A., Hess L.R. \& Quesenberry K.E. 2000. Intestinal string foreign body in an adult Umbrella Cockatoo (Cacatua alba). Journal Avian Medicine and Surgery. 14(4): 257-263.

2 Adamamma-Moraitou K.K., Prassinos N.N., Patsikas M.N., Psychas V., Tsioli B. \& Rallis T.T. 2004. Sclerosing encapsulating peritonitis in a dog with leishmaniasis. Journal of Small Animal Practice. 45(2): 117-121.

3 Barnes H.J. \& Fletcher O.J. 2016. Hemic system. In: Abdul-Aziz T., Fletcher O.J. \& Barnes H.J. (Eds). Avian Histopathology. 4th edn. Jacksonville: American Association of Avian Pathologists, pp.1-16.

4 Bartoli C.R. \& Godleski J.J. 2010. Blood Flow in the Foreign-Body Capsules Surrounding Surgically Implanted Subcutaneous Devices. Journal of Surgical Research. 158(1): 147-154.

5 Champour M. \& Ojrati N. 2014. Ventriculotomy for the removal of a foreign body in a common myna (Acridotheres tristis): a case report. Veterinarni Medicina. 59(6): 319-323.

6 Doneley B. 2010. Avian medicine and surgery in practice. In: Avian Medicine and Surgery in Practice: Companion and Aviary Birds. 2nd edn. Boca Raton: CRC Press, pp.156-172.

7 Hayati F., Lakzian A., Shariati E., Bakhtiari J., Sayyah N., Masoudifard M. \& Vakili T. 2011. Surgical removal of a ventricular foreign body from a common myna (Acridotheres tristis): a case report. Veterinarni Medicina. 56(22): 97-100.

8 Hoefer H. \& Levitan D. 2013. Clinical Reports Perforating Foreign Body in the Ventriculus of an Umbrella Cockatoo (Cacatua alba). Avian Medicine and Surgery. 27(2): 128-135.

9 Huchzermeyer F.W. \& Cooper J.E. 2000. Short communications: Fibriscess, not abscess, resulting from a localised inflammatory response to infection in reptiles and birds. Veterinary Record. 147(18): 515-517.

10 Instituto Ambiental do Paraná (IAP). 2015. Portaria IAP nº 173, de 02 de setembro de 2015.

11 Instituto Ambiental do Paraná (IAP). 2015. Portaria IAP no 246 de 17 de dezembro de 2015.

12 International Union for Conservation of Nature and Natural Resources (IUCN). 2018. Red List of Threatened Species, IUCN- Bird Life International Ara ararauna. The IUCN Red List of Threatened Species.

13 Jcullen J.M. \& Stalker M.J. 2007. Liver and biliary system. In: Maxie M.G. (Ed). Jubb, Kennedy \& Palmer's Pathology of Domestic Animals. v.2. 6th edn. Philadelphia: Elsevier, pp.238-334.

14 Lopes P.C., Adelman J., Wingfield J.C. \& Bentley G.E. 2012. Social context modulates sickness behavior. Behavioral Ecology and Sociobiology. 66: 1421-1428.

15 Marietto G.G. \& Andreatti Filho R. 2006. Doenças do Sistema Digestório das Aves (Revisão Bibliográfica). Nosso Clínico. 9: 46-56.

16 Shivaprasad H.L. 2002. Pathology of Birds - an overview. In: Proceedings of C.L. Davis Foundation Conference on Gross Morbid Anatomy of Animals, AFIP, The Royal College of Pathologists (Washington DC, USA). pp.1-48.

17 Tannoury J.N. \& Abboud B.N. 2012. Idiopathic sclerosing encapsulating peritonitis: Abdominal cocoon. World Journal of Gastroenterology. 8(17): 1999-2004.

18 Taylor W.M. 2016. Pleura, pericardium, and peritoneum: The coelomic cavities of birds and their relationship to the lung-air sac system. In: Speer B.L. (Ed). Current Therapy in Avian Medicine and Surgery. Oakley: Elsevier, pp.345362. 